\title{
PARA ARRISCAR SÓ É PRECISO CORAGEM?
}

DOI: 1014211/regepe.v5i3.404

Artigo recebido em: 16/08/2016 Artigo aprovado em: 09/09/2016

Nilvane Boehm Manthey - Universidade do Estado de Santa Catarina - UDESC ${ }^{1}$ Estela Maria Hoffmann - Universidade do Vale do Itajaí - UNIVALI ${ }^{2}$

\begin{abstract}
Resumo: O presente caso de ensino busca apresentar os dilemas que envolvem a decisão de internacionalizar uma empresa. As informações foram obtidas a partir de fontes de dados primárias e secundárias: entrevista com o proprietário da empresa e consulta ao site da empresa, respectivamente. O caso de ensino trata de uma empresa desenvolvedora de softwares, especializada em concessões municipais de gestão de saneamento básico, a qual teve a oportunidade de expandir seus negócios para Portugal. O nome "HighTech Informática", utilizado no caso de ensino, é fictício, conforme solicitado pelos sócios. Devido às diferenças culturais entre os dois países, algumas alterações deveriam ser feitas na proposta de internacionalização. Para tanto, novos investimentos também precisariam ser realizados para a consolidação do contrato. Temendo os riscos, os proprietários discutem os prós e os contras de realizar a internacionalização e o dilema do caso estimula os alunos a buscar soluções proporcionando a compreensão das teorias de internacionalização.
\end{abstract}

Palavras-chave: Caso para Ensino; Estratégias de Internacionalização; PMEs.

\section{JUST NEED THE COURAGE TO TAKE SOME RISK?}

Abstract: This teaching case seeks to present the dilemmas involving the decision to internationalize a company. The information was obtained from primary and secondary data sources: an interview with the business owner and consulting the site of the surveyed company. The teaching case deals with the HighTech company, fictitious name created to characterize the company that develops software for municipal concessions sanitation, which had an opportunity to expand its business in Portugal. Due to cultural differences between the two countries, some changes should be made in the proposed internationalization. To do that, new investments would be necessary for contract consolidation. Fearing the risks, the company owners discuss the pros and cons of carrying out the internationalization and the case of the dilemma encourages students to seek solutions providing the

1 Endereço: Rua 806 b, 850, Bairro Alto São Bento, Itapema - SC, CEP: 88220-000.

E-mail: nilvane_9@hotmail.com

2 E-mail: estela_hoff@hotmail.com

MANTHEY, N. B.; HOFFMANN, E. M. Para arriscar só é preciso coragem? Revista de

Empreendedorismo e Gestão de Pequenas Empresas, v.5, n.3, 2016. 
understanding of internationalization theories. The practical example provides students visualize the organizational reality by raising the issues involved in a process of internationalization.

Keywords: Teaching Case; Internationalization Strategies; PMEs.

\section{Introdução}

Não é fácil arriscar, é preciso ter muita coragem. José e Carlos andavam ansiosos pela sala iluminada por uma grande janela. Somente o barulho do climatizador interrompia o silêncio do local. Neste cenário de incerteza é construído o caso de ensino proposto.

A empresa de pequeno porte catarinense, que já obtinha reconhecimento no mercado nacional como desenvolvedora de softwares, nunca teve a ambição de internacionalizar seus negócios. A partir de um software de saneamento básico, Sansys, desenvolvido para padronizar o sistema em 14 cidades do estado de Santa Catarina, os sócios receberam a proposta para adaptar o modelo brasileiro à realidade portuguesa. Ambos estavam pensativos, em busca de alternativas que resolvessem o impasse: realizar os investimentos necessários para expandir para Portugal as operações da "HighTech Informática" e aproveitar a oportunidade de entrar no mercado europeu, ou não arriscar e permanecer atendendo apenas o mercado brasileiro?

Esse impasse poderia acabar com a oportunidade de expandir os negócios para fora do Brasil. Agora que estavam com tudo pronto, qual o melhor caminho a seguir? Desistir diante da oportunidade? Essas são angústias constantes de empresários que querem expandir os seus negócios para os mercados internacionais. José e Carlos vivenciavam na pele o dilema.

\section{Descrição da Empresa}

O caso de ensino trata de uma empresa desenvolvedora de softwares, especializada em concessões municipais de gestão de saneamento básico, 
localizada na cidade de São José, Santa Catarina. A empresa de pequeno porte, denominada "HighTech Informática" (nome fictício criado, conforme solicitação dos proprietários), atuava no desenvolvimento de softwares para concessões no estado de Santa Catarina, quando surgiu a oportunidade de internacionalizar a empresa com um contrato em Portugal.

\section{Apresentação Detalhada da Problemática}

Tudo começou em 2011, quando Carlos e José, os dois sócios da "HighTech Informática", viram a necessidade de desenvolver um software padronizado para o setor de saneamento. Essa era uma área em franca expansão e os dois, apesar de possuírem personalidades bem diferentes um do outro, estavam em sintonia e com a mesma visão empreendedora: o investimento tecnológico na área de saneamento básico é uma grande oportunidade de negócio.

O software para saneamento básico Sansys tornou-se o carro-chefe da empresa, que atendia a vários clientes. Uma de suas parcerias era uma concessionária privada de Santa Catarina, que administrava 14 cidades. Nessa concessionária, o software de gestão era diferente de uma cidade para outra e dificultava a padronização das informações. Percebendo essa dificuldade, José e Carlos ofereceram um software que atendesse todas as cidades. Os dois trabalharam arduamente nesse projeto de padronização até concluí-lo com êxito, surgindo o Sansys.

Foi aí que novos caminhos começaram a se abrir para a "HighTech Informática". A empresa portuguesa "BPI" ganhou a concessão de saneamento básico de uma cidade vizinha de onde atuava a "HighTech Informática". Os portugueses ficaram sabendo do software Sansys e contrataram o serviço de José e Carlos. O Sansys agradou os empresários portugueses, pois possuí muitos recursos, considerado muito mais dinâmico e completo. Logo a parceria se estendeu para outras cidades brasileiras e a empresa ganhou novas concessões.

Certo dia, João, que era um dos diretores da empresa "BPI", veio de Portugal para o Brasil e quis conhecer pessoalmente José e Carlos. Foi neste encontro que eles ficaram sabendo que em Portugal praticamente todo 0 
saneamento é privado e que a empresa "BPI" era detentora de $80 \%$ de todas as concessões. Os sócios da "HighTech Informática" foram convidados a realizar uma apresentação do Sansys para o empresário português, que relatou o problema que a empresa "BPI" vivenciava em Portugal: a falta de um software padronizado, pois cada concessão possuía um software diferente, o que dificultava a gestão: "estamos muito insatisfeitos com isso, precisamos melhorar urgentemente esse quesito e acho que vocês podem nos ajudar", explicou João.

Assim, surgiu um novo e atraente convite: "gostamos muito do trabalho de vocês. Esse software tem todas as funcionalidades que nós precisamos e, além disso, ele é padronizado, o que facilita muito o nosso trabalho. Vocês já pensaram em atuar em outros países? Que tal expandir essa nossa parceria para Portugal? Temos a concessão de praticamente todo o país", disse João.

Carlos e José ficaram emocionados. Aquilo era algo inimaginável para eles até então. Seria uma oportunidade única.

“- É realmente muito tentador" - respondeu José, com um sorriso que não disfarçava a felicidade. José, sempre animado e extrovertido, era um sócio movido à desafios e aquele, sem dúvidas, seria incrível para ele.

No entanto, Carlos, que era mais reservado e contido, ponderou:

“- Claro que temos interesse, mas acredito que precisaremos discutir muito bem cada questão, pois temos realidades diferentes, não é mesmo?"

“- Com certeza, Carlos." Concordou João, que continuou: "Já proponho o seguinte: preparem um material para apresentar aos diretores de Portugal. Marcaremos para a próxima semana uma videoconferência onde apresentaremos o software detalhadamente e eles também poderão explicar melhor como é o funcionamento da concessão por lá. Assim discutiremos todos os detalhes necessários. Aguardarei vocês".

Naquela mesma tarde, Carlos e José iniciaram os preparativos para a apresentação. Estavam aliviados já que a língua não seria um impasse para a internacionalização da empresa, pois conseguiam se comunicar perfeitamente. Mas mesmo assim, Carlos ainda estava inseguro. José era só empolgação.

$\mathrm{Na}$ semana seguinte, aconteceu a reunião via videoconferência com todos os diretores da empresa portuguesa "BPI". A reunião foi muito tranquila e logo os portugueses mostraram-se receptivos à ideia do Sansys. Para os diretores da "BPI", 
o software era perfeito para atender o principal problema da empresa: a falta de padronização nos programas de saneamento, que atendia diversas cidades.

Começaram então as tratativas para a efetivação dessa parceria. A proposta acertada era um projeto piloto de seis meses com a implantação do software em uma pequena cidade portuguesa na ilha da Madeira. Ao fim do período de testes, o software seria avaliado. A implementação nas demais unidades ocorreria após essa avaliação.

Organizaram a implementação inclusive toda a documentação necessária. Carlos conversou com José sobre a possibilidade de viajarem a Portugal para conhecer de perto a realidade do saneamento no país, mas José achava um gasto desnecessário, já que os diretores da "BPI" passaram a certeza e a tranquilidade de que o Sansys era adequado e atendia todos os requisitos necessários. Mas ainda prudente, Carlos resolveu aproveitar os meses que antecipavam a instalação do software em Portugal e quis adiantar alguns detalhes, por isso solicitou o contato de um representante da cidade em que instalariam o Sansys para trocar informações. O contato em Portugal era Maria, a coordenadora responsável por boa parte das concessões da BPI.

“- Maria, boa tarde. Quem está falando é o Carlos, da empresa "HighTech Informática" do Brasil, tudo bem? Gostaria de conversar melhor com vocês sobre como será esse processo e ter mais informações sobre a concessão piloto que faremos. Podemos marcar uma reunião?"

“- Olá, Carlos! Claro que sim. Eu coordeno a concessão de várias cidades aqui da região, acredito que isso dará um parâmetro geral da nossa realidade e assim vocês conseguirão entender melhor como tudo funciona por aqui."

Informações foram trocadas e tudo parecia bem, até que um dia Carlos recebeu um telefonema de Maria.

“- Carlos, estamos observando melhor o software de vocês, mas estamos achando ele muito 'amarrado'. Há controles muito complexos. A gente precisa resolver isso."

“- Maria, não entendo o que você quer dizer com controles complexos, podes me dar um exemplo?"

“- Vou dar um exemplo bem simples: aí no Brasil a leitura da conta de água é realizada todo mês, diretamente nas casas, o 'leiturista' vai lá e faz. Já aqui em 
Portugal não existe isso, o 'leiturista' vai esporadicamente, tipo de 6 em 6 meses. 0 morador é que liga e informa o consumo ou entra no site, entendeu? A preocupação é do morador em dizer o quanto está consumindo. O 'leiturista' só confirma de tempos em tempos, e se nesse período o morador estiver mentindo, a multa é gigantesca [....] Isso é crime, tem uma série de punições, então ninguém faz, todo mundo tem essa consciência".

“- Maria vou Ihe mandar um questionário de implantação, precisamos verificar mais exemplos como esses, pois as alterações não são tão simples. Para você ter uma ideia, são mais de mil tabelas e a mudança de um quesito exige a atualização em muitas outras tabelas. O software foi desenvolvido pensando na realidade brasileira. Foi necessário criar diversos mecanismos para evitar fraudes, por isso ele tem essas características que, pelo visto, não é necessário para vocês. Nós não nos preocupamos com isso porque o João nos garantiu que o software poderia ser usado em Portugal, sem problema algum...".

“- Eu sei Carlos. Eu também achei que o software seria muito bom para nós, mas tem alguns detalhes que não se encaixam com a nossa realidade. Será que conseguimos fazer essas adaptações?"

“- Bem, isso vai demandar tempo e dinheiro. Nosso valor contratual terá de ser revisto e, além disso, será muito arriscado para nós, afinal nosso contrato é de apenas seis meses, só depois disso vocês nos darão o contrato definitivo. Agora preciso avaliar melhor a situação, para decidir o que fazer".

“- Claro, Carlos. Analise bem a situação, mas infelizmente será impossível utilizar o programa da maneira que ele está atualmente e já adianto que não poderemos alterar o valor contratual. Vocês terão que bancar com estes gastos de alteração no programa."

E assim iniciava o dilema de Carlos e José!

Eles sempre foram bem diferentes um do outro, mas essa união foi fundamental para o crescimento de ambos. Cada um do seu jeito: José, administrador de empresas, sempre brincalhão, gosta de interagir com todos, faz amizades facilmente, usava dessas habilidades para conseguir novos contatos para a empresa e sempre conseguia descobrir informações importantes sobre o mercado. Já Carlos, graduado em Informática, é mais compenetrado, introspectivo, observador e, além disso, dispõe de uma criatividade ímpar. Carlos sabia criar MANTHEY, N. B.; HOFFMANN, E. M. Para arriscar só é preciso coragem? Revista de Empreendedorismo e Gestão de Pequenas Empresas, v.5, n.3, 2016. 
soluções simples para os problemas do cotidiano das pessoas. Essa união sempre deu muito certo. Os dois se complementavam, mas agora, diante desse impasse, era a primeira vez que estavam apreensivos e discordando sobre as decisões a tomar.

José defendia que não deveriam desistir. Que eles deveriam buscar novos investidores para ajudar a financiar as mudanças que seriam necessárias fazer no software. Acreditava que deveriam ir a Portugal, ver de perto como funciona o sistema de saneamento básico lá e buscar até mesmo um financiamento se fosse necessário.

Já Carlos estava convicto de que não deveriam seguir adiante. "É muito arriscado", dizia ele. Carlos acreditava que buscar empréstimos poderia ser a ruína da empresa tanto no exterior, quanto no Brasil. O contrato com Portugal só estaria definitivamente concluído após seis meses de um projeto piloto. "E se falharmos? E se não gostarem das adaptações no software? Todo o investimento será em vão, já que aqui no Brasil não teremos como utilizá-lo. Como pagaremos as dívidas?".

Os empresários que até então conseguiram conquistar o mercado facilmente, alcançaram novos clientes com precisão e criaram grandes oportunidades, estavam agora diante de um verdadeiro impasse.

José decidiu ir atrás de investidores. Acreditava que seria fácil conseguir empresários interessados em investir nessa área, afinal era uma área que estava aparecendo cada vez mais na mídia. O saneamento básico envolve toda a questão ambiental, a falta de água potável no mundo, enfim, eram vários os fatores que faziam José ficar confiante.

Mas infelizmente não foi bem assim que aconteceu. Apesar da insistência de José, ele não conseguiu os investidores. Toda a sua "lábia" e poder de persuasão não foram suficientes para convencer os investidores, que estavam diante de um mercado instável.

Mesmo chateado, José não desistiu.

“- Carlos, precisamos de um financiamento. Não podemos deixar de investir no mercado externo por causa disso. Já temos um bom cliente em potencial, temos um bom produto. Só precisamos de um valor para fazer os ajustes necessários. Temos certeza que vamos conseguir conquistar esse contrato". 
“- Você sabe a minha opinião, José. Eu não tenho capital. Larguei tudo para montar essa empresa. Já se passaram seis anos desde que fundamos a "HighTech Informática". Fomos crescendo aos poucos, trabalhamos duro no início, de domingo a domingo. Eu não posso correr o risco de colocar tudo fora. Estamos indo bem aqui no Brasil. Somos bons no que fazemos, não é à toa que nos tornamos referência em fabricação de software. Mas você sabe o quanto tudo isso custou, não sabe?!".

“- Eu sei, Carlos! Quando te convidei para ser meu sócio, eu vi em você todo esse potencial. Não te 'tirei' do seu antigo emprego para te prejudicar, pelo contrário, quando vi a oportunidade que tínhamos diante da expansão da área do saneamento básico no país e vi que poderíamos conquistar muito mercado no Brasil, acreditei muito que venceríamos. Mas agora é hora de expandir nossos horizontes. É preciso arriscar mais. É preciso ter mais coragem. A mesma coragem que você teve quando largou do seu emprego para assumir comigo o desafio de montar a empresa, essa mesma coragem é preciso ter agora."

O financiamento era a única saída. Mas os dois sócios não conseguiam chegar a um acordo. E a empresa portuguesa pressionava por uma resposta rápida. Naquela tarde, eles deveriam dar a resposta à "BPI". Os dois sócios permaneciam sem saber o que fazer. José e Carlos dividiam a mesma sala, o mesmo silêncio, a mesma dúvida. Em poucos momentos o futuro dos dois e da empresa teria de ser decidido.

“- Você tem muito medo de arriscar, Carlos".

“- E você não sabe que um bom empresário também precisa ter medo. Nem só de coragem se constrói uma empresa".

Questão Problema: Os sócios da empresa "HighTech Informática" devem assumir o risco de entrar no mercado internacional?

\section{Análise do Caso e Conexão com a Literatura}

A temática a ser discutida no caso trata dos modos de entrada e as teorias de internacionalização, especificamente da teoria econômica de custos de transação e a teoria comportamental de Uppsala. 


\section{Questão 1}

1) Qual o principal aspecto que dificultou a comercialização do software Sansys em Portugal? Como teorias de internacionalização tratam desse aspecto?

O exemplo dado por Maria para explicar a Carlos a diferença na necessidade do software para Portugal resume o principal entrave para a internacionalização da empresa "HighTech Informática": a cultura diferente entre os países. Embora Brasil e Portugal compartilhem a mesma língua e alguns traços que hoje caracterizam a cultura brasileira são derivados da cultura portuguesa, questões culturais relativas aos costumes do povo são pontos relevantes que influenciam na internacionalização da empresa. O software adequado às necessidades do Brasil, desenvolvido com diversos mecanismos para evitar fraudes, não é necessário em Portugal.

Para compreender o processo de internacionalização de empresas é importante refletir sobre os pressupostos das Teorias de Internacionalização. A internacionalização é um processo no qual a empresa envolve-se de forma crescente em operações fora do país de origem. O envolvimento pode incluir matérias-primas ou produtos acabados da empresa ou ainda, etapas de sua cadeia de valor (CARNEIRO; DIB, 2007).

As Teorias de Internacionalização podem ser classificadas em Teorias Econômicas e Teorias Comportamentais (CARNEIRO; DIB, 2007). Os pressupostos das teorias econômicas em internacionalização defendem a tomada de decisão sobre internacionalização com prevalência de soluções racionais que orientem a um caminho de decisões que traga a maximização dos retornos econômicos (CARNEIRO; DIB, 2007).

O pressuposto da abordagem comportamental em internacionalização é o de que o processo de internacionalização depende de atitudes, percepções e comportamento dos tomadores de decisão, orientados para a busca de redução de risco nas decisões sobre onde e como expandir (CARNEIRO; DIB, 2007).

Relacionado às teorias de internacionalização de aspectos comportamentais, tem-se os estudos de Johanson e Vahlne, com a Teoria de 
Uppsala, sugerindo que o processo de internacionalização ocorre de forma incremental por causa das incertezas e imperfeições das informações recebidas sobre o novo mercado, e que as empresas tendem a internacionalizar para países com menor distância psíquica (língua, cultura, diferenças existentes entre regiões e entre setores industriais, bem como as diferenças entre indivíduos). $\mathrm{Na}$ visão da Escola de Uppsala, a distância psíquica leva as firmas a selecionarem os mercados de entrada em ordem crescente da distância percebida, o que pode ou não coincidir com distância geográfica (JOHANSON; VAHLNE, 2009).

A Teoria de Uppsalla supõe que a sequência de modos de operação se inicia com um envolvimento leve, geralmente representado por exportação direta, quando se tem a oportunidade de adquirir conhecimentos sobre o novo mercado. $O$ envolvimento se aprofunda a partir do aumento desses conhecimentos e da melhoria dos canais de informação, podendo a firma chegar a um alto envolvimento, representado pelo estabelecimento de subsidiárias no país estrangeiro. A sequência na seleção de mercados abrange a entrada sucessiva em mercados cada vez mais psiquicamente distantes, à medida que a firma ganha experiência de operações estrangeiras (JOHANSON; VAHLNE, 2009).

A Teoria de Uppsalla pressupõe que a fronteira da incerteza está relacionada com a distância psíquica: quanto maior a diferença entre o país de origem e o país estrangeiro em termos de desenvolvimento, nível e conteúdo educacional, idioma, cultura, sistema político, entre outros, maior o nível de incerteza (JOHANSON; VAHLNE, 2009).

Johanson e Mattsson (1988) observaram as redes de relacionamentos como importantes para a entrada de empresas em novos mercados. Assim, os relacionamentos, tanto estritamente de negócios, quanto pessoais, podem ser usados como pontes para a entrada em outras networks (JOHANSON; MATTSSON,1988).

Relacionamentos próximos e duradouros entre parceiros de negócios são importantes. Dentro ou fora do mesmo país, os relacionamentos se desenvolvem por meio de um processo de aprendizado experiencial, pelo qual as empresas aprendem sobre os recursos e capacidades da outra parte e, gradualmente, aumentam seu compromisso e tendem a diminuir a distância psíquica (JOHANSON; VAHLNE, 2009). 
No âmbito das teorias econômicas, a Teoria dos Custos de Transação considera que os custos de entrada de uma empresa em mercados internacionais não se resumem a custos de produção: existem também os custos de transação, ou seja, os custos que os agentes enfrentam quando recorrem ao mercado para adquirir equipamentos, insumos ou serviços, ou quando estabelecem uma "interface" com outro agente (ANDERSON; GATIGNON, 1986).

A Teoria dos Custos de Transação pressupõe que o grau de controle está diretamente relacionado com o grau de conhecimento experiencial internacional da empresa e observa incertezas ambientais relativas a diferenças socioculturais (entre regiões e indivíduos) (ANDERSON; GATIGNON, 1986).

O Paradigma Eclético de Dunning apresenta o pressuposto OLI para explicar o processo de internacionalização de empresas.

Vantagens de Propriedade ou Ownership (O) ou vantagens de propriedade: são vantagens exclusivas da empresa, ao menos temporariamente, e que the atribuem superioridade em relação aos seus concorrentes, como patentes, tecnologias, estrutura organizacional, entre outras, podendo ser de caráter estrutural que deriva da posse ou do acesso exclusivo e privilegiado a recursos que podem se tornar ativos ou de posse de ativos intangíveis, como patentes, marcas, conhecimento tecnológico, ou de caráter transacional (Ot). Em síntese, é a capacidade da empresa de gerenciar de maneira hierárquica as atividades em nível internacional (DUNNING, 1988).

Location (L) ou vantagens específicas da localização: estão relacionadas aos locais onde as empresas multinacionais implantam as operações no exterior, ou seja, às condições dos países de destino, sendo elas institucionais, econômicas e/ou culturais, que podem influenciar o desempenho da subsidiária, incluindo o acesso e uso de fatores locais, até políticas de incentivo.

Internalization (I) ou vantagens específicas de internalização: apresenta a estrutura para avaliação de modos alternativos de como as empresas multinacionais organizam a criação e exploração de seus núcleos de competências, considerando os atrativos locacionais de diferentes países ou regiões e relacionam-se com a exploração internamente, de competências próprias da multinacional ao invés de explorá-las por meio do mercado. Para Dunning, a empresa multinacional decidirá 
localizar sua produção onde possa usufruir dessas três vantagens, as quais devem estar presentes simultaneamente (DUNNING, 1988).

\section{Questão 2}

2) Quais são os modos de entrada em internacionalização de empresas? Como se aplicam ao caso da empresa "HighTech Informática"?

Modos de entrada em internacionalização estão relacionados às opções das empresas quando da decisão sobre a forma de entrada no mercado internacional (ANDERSON; GATIGNON, 1986).

Um modo de entrada em internacionalização é o Investimento Estrangeiro Direto (IED).

"Por investimento estrangeiro direto entende-se a aquisição, no exterior, de ativos fixos, tais como plantas e equipamento, de forma que o controle da sua operação fique com a empresa adquirente" (MARIOTTO et al., 2007, p. 45). O que leva uma empresa para o IED são "os lucros que podem ser obtidos pela empresa mediante controle do empreendimento no estrangeiro, e não a taxa de juros" (HYMER, 1970 apud MARIOTTO et al., 2007, p. 47).

Para competir em país estrangeiro, a empresa precisa dispor de vantagens competitivas sobre os competidores locais, como um produto melhor ou mais barato. Cabe ressaltar que de saída, as empresas que se instalam em um mercado estrangeiro sofrem uma desvantagem em relação aos concorrentes (ônus de ser estrangeiro - liability of foreignness).

Para ser válida a instalação da empresa no país, ela precisa de vantagens sobre os concorrentes locais "de tal magnitude que supere as desvantagens que ela tem perante as empresas locais por ser estrangeira (língua, cultura, desconhecimentos, economia, política, fornecedores, discriminação pelo governo por ser estrangeira, clientes)" (HYMER, 1970 apud MARIOTTO et al., 2007, p. 47).

No entanto, há situações em que as vantagens da firma no país estrangeiro podem ser maiores que no mercado doméstico, por exemplo: "quando a concorrência no país doméstico é muito grande e os fatores de produção como mão 
de obra qualificada e capital são muito caros" (HYMER, 1970 apud MARIOTTO et al., 2007, p. 49).

Algumas empresas conseguem competir em um mercado estrangeiro com empresas locais, "criando barreiras à concorrência (poder de mercado) no mercado estrangeiro e assim superam as desvantagens inerentes à condição de estrangeiro" (HYMER, 1970 apud MARIOTTO et al., 2007, p. 50).

Outras empresas, para operarem em mercado estrangeiro, optam por fazer IED no país estrangeiro, mesmo que poderiam explorar seu produto ou licenciar empresas nesse mercado para fazer uso de suas vantagens competitivas. Assim, a empresa busca pelo controle do empreendimento no país estrangeiro, obter Poder de Mercado nesse país, para tirar o maior proveito possível: "1ํo eliminando o concorrente (comprando-o); $2^{\circ}$ explorar de forma mais produtiva o licenciamento, uma vantagem que ela possui no seu mercado doméstico e que poderia usar no mercado estrangeiro" (HYMER, 1970 apud MARIOTTO et al., 2007, p. 50).

A Teoria do Ciclo de Vida do Produto explica que as vantagens competitivas que permitem uma empresa competir com vantagem em um primeiro momento do ciclo de vida do produto é a mesma que "permite às empresas penetrar em mercados multinacionais com sucesso, pois com a 'maturação' do ciclo de vida do produto, este torna-se mais padronizado e mais intensivo em mão de obra de baixa qualificação" (HYMER, 1970 apud MARIOTTO et al., 2007, p. 54).

Teorias de Internalização ou integração caracterizam-se pela decisão de uma firma em realizar atividades da sua cadeia de produção dentro da empresa em vez de contar com outras empresas para realizarem essas atividades e comprar delas seus insumos ou vender a elas seus produtos. "A empresa internaliza atividades quando percebe que, se contasse com outras empresas do mercado para realizar essas atividades, o custo seria maior (custos de transação)" (MARIOTTO et al., 2007, p. 58).

A localização geográfica também é importante em modos de entrada em mercados internacionais, pois há a tendência à concentração geográfica de atividades especializadas ligadas a certo ramo em determinados locais ao redor do mundo. Economias de aglomeração: derivam de conhecimento ou competências geradas por firmas do local e que acabam sendo aproveitadas por outras empresas 
ali instaladas, ou seja, "as economias derivam de knowledge spillovers ou derramamento de conhecimento" (MARIOTTO et al., 2007, p. 65).

Aliando a teoria ao caso da empresa "HighTech Informática" observa-se que a empresa não realizaria IED (Investimento estrangeiro direto), pois para o desenvolvimento de seu produto, o software Sansys, não há necessidade de aquisição de ativos físicos. Uma vantagem da empresa "HighTech Informática" que despertou o interesse da empresa portuguesa é a padronização dos softwares de saneamento e, no caso da concretização da internacionalização da empresa, este aspecto poderia ser trabalhado visando gerar Poder de Mercado, com a diferenciação crescente e constante do seu software a fim de atender todo o mercado português e, ocasionalmente, visualizar outros mercados europeus. O ônus de ser estrangeiros (liability of foreignness), embora existente, poderia ser potencialmente reduzida com o fortalecimento das redes de relacionamento, o que no caso do produto da Sansys a maior facilidade reside no fato de atender a um cliente específico, e não a vários clientes.

A entrada esperada no mercado português ocorreria seguindo a Teoria do Ciclo de Vida do Produto, pois a empresa utilizaria um produto já existente para entrar em mercado internacional. No entanto, com a troca de informações entre Maria e Carlos, observou-se que este produto desenvolvido para atender necessidades brasileiras não atenderia o mercado português. Isso incorreria em custos de transação, ou seja, custos para adequar o produto ao mercado português. Uma solução para minimizar os custos de transação e ainda entrar no mercado português seria a de buscar parcerias com empresas em Portugal, licenciando a marca e diluir os custos entre os parceiros.

\section{Questão 3}

3) Sendo você o gestor da empresa "HighTech Informática" que decisão tomaria analisando a situação da empresa e as teorias de internacionalização? Explique.

Para responder esta questão sugere-se a reflexão com o auxílio do artigo de Carneiro e Dib (2007) que observam a importância de considerar cinco questões em 
processos de internacionalização: por quê, o quê, quando, onde e como as empresas internacionalizam (suas atividades). A síntese dessas questões é apresentada na Figura 1.

FIGURA 1 - QUESTÕES BÁSICAS PARA O PROCESSO DE INTERNACIONALIZAÇÃO DE UMA EMPRESA

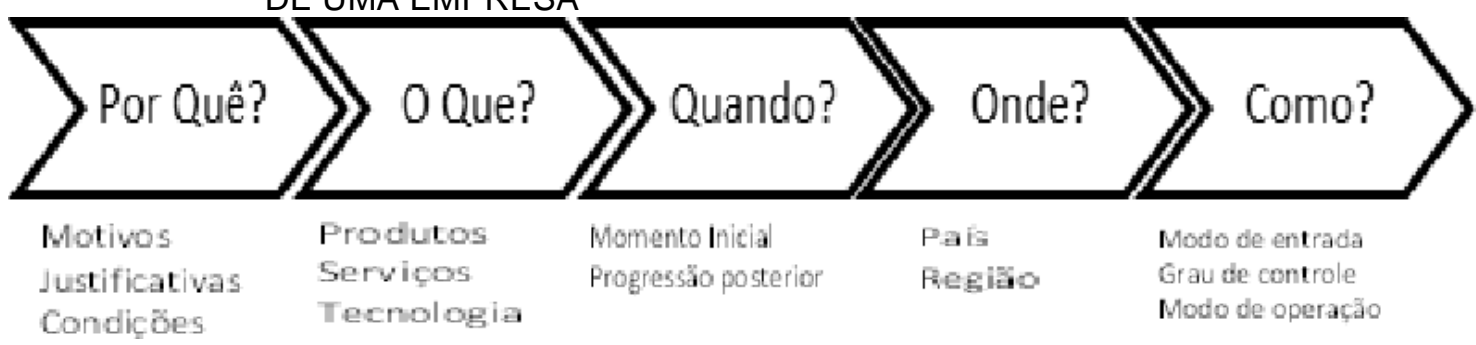

FONTE: Carneiro e Dib (2007).

Com base no artigo e nas teorias estudadas, sugere-se desenvolver um quadro analisando as cinco questões propostas por Carneiro e Dib (2007), como o Quadro 1 apresenta. 
QUADRO 1 - QUESTÕES PERTINENTES AO PROCESSO DE INTERNACIONALIZAÇÃO ALINHADAS AO CASO DA EMPRESA "HIGHTECH INFORMÁTICA"

\begin{tabular}{|c|c|c|c|c|c|}
\hline & Por quê? & O quê? & Quando? & Onde? & Como? \\
\hline $\begin{array}{l}\text { Justificar } \\
\text { com a a } \\
\text { experiênci } \\
\text { a da } \\
\text { empresa }\end{array}$ & $\begin{array}{l}\text { Oportunidade } \\
\text { surgiu a partir de } \\
\text { relacionamentos. } \\
\text { Aproveitar a } \\
\text { oportunidade e } \\
\text { expandir para } \\
\text { novos mercados. }\end{array}$ & $\begin{array}{lr}\text { Comercializar } & 0 \\
\text { Software } & \text { de } \\
\text { gestão Sansys. }\end{array}$ & $\begin{array}{lr}\text { Assim que } & \text { que } \\
\text { obtiver } & 0 \\
\text { conhecimento } & \\
\text { das } & \\
\text { necessidades } \\
\text { do mercado } \\
\text { em Portugal e } \\
\text { adequar o } \\
\text { software para } \\
\text { atender a } \\
\text { estas r } \\
\text { necessidades. }\end{array}$ & Portugal & $\begin{array}{l}\text { Dilema do } \\
\text { caso }\end{array}$ \\
\hline $\begin{array}{l}\text { Justificar } \\
\text { com a } \\
\text { teoria }\end{array}$ & $\begin{array}{l}\text { Momento Inicial: } \\
\text { Empreendedoris } \\
\text { mo Internacional: } \\
\text { Procura de novos } \\
\text { mercados; } \\
\text { atendimento a } \\
\text { solicitações } \\
\text { espontâneas; } \\
\text { reestruturação da } \\
\text { indústria. } \\
\text { Momento } \\
\text { posterior: Poder } \\
\text { de mercado: } \\
\text { Otimizar recursos } \\
\text { ou competências } \\
\text { e explorar } \\
\text { imperfeições via } \\
\text { estruturais via } \\
\text { posições de } \\
\text { conluio mólio. ou } \\
\text { monopólio. }\end{array}$ & $\begin{array}{l}\text { Paradigma } \\
\text { Eclético, Uppsala, } \\
\text { Network e } \\
\text { Empreendedoris } \\
\text { mo Internacional: } \\
\text { Sem restrições } \\
\text { em termos de } \\
\text { produtos, } \\
\text { serviços, } \\
\text { tecnologias ou } \\
\text { atividades. }\end{array}$ & $\begin{array}{l}\text { Modelo de } \\
\text { Uppsalla: } \\
\text { Momento } \\
\text { inicial: } \\
\text { saturação do } \\
\text { mercado } \\
\text { doméstico; } \\
\text { Expansão: } \\
\text { conforme o } \\
\text { conhecimento } \\
\text { for } \\
\text { gradualmente } \\
\text { obtido pela } \\
\text { experiência } \\
\text { internacional. }\end{array}$ & $\begin{array}{l}\text { Modelo de } \\
\text { Uppssala: } \\
\text { Para } \\
\text { países } \\
\text { com } \\
\text { "distância } \\
\text { psíquica" } \\
\text { em } \\
\text { relação ao } \\
\text { mercado } \\
\text { doméstico } \\
\text { menor no } \\
\text { primeiro } \\
\text { momento } \\
\text { e, depois, } \\
\text { gradualme } \\
\text { nte } \\
\text { crescente. }\end{array}$ & $\begin{array}{l}\text { Paradigma } \\
\text { Eclético: } \\
\text { Exportação, } \\
\text { investimento } \\
\text { direto ou } \\
\text { licenciament } \\
\text { o, dada a a } \\
\text { melhor } \\
\text { combinação } \\
\text { das } \\
\text { vantagens } \\
\text { de } \\
\text { propriedade, } \\
\text { localização } \\
\text { ou } \\
\text { internalizaçã } \\
\text { o. }\end{array}$ \\
\hline
\end{tabular}

FONTE: Elaborado pelas autoras com base em Carneiro e Dib (2007).

A elaboração do quadro é sugestiva e pode incluir as análises dos autores (CARNEIRO; DIB, 2007) para todas as teorias estudadas. O quadro permite perceber as similaridades e diferenças entre a realidade da empresa "HighTech Informática", relacionando as explicações das diversas teorias de internacionalização. Pode-se perceber que nenhuma teoria explica plenamente o processo de internacionalização da empresa estudada, no entanto, percebe-se similaridades com diversas delas.

A questão como é justamente o dilema do caso. Neste quesito, cada aluno ou grupo de alunos poderá explorar a possibilidade que acredita ser melhor ao caso. 
Cabe ao professor orientar a discussão e explorar as ideias dos alunos, desenvolvendo um debate, ressaltando que não há certo ou errado, mas várias possibilidades.

\section{Decisão da Empresa "HighTech Informática"}

A empresa "HighTech Informática" optou por não realizar a internacionalização. Como não possuíam o capital necessário e não conseguiram investidores para custear as alterações no programa, os sócios acharam arriscado pedir financiamento bancário. O projeto seria um piloto de seis meses, sem garantias de contratação posterior. Sendo assim, optaram por desistir do negócio e seguir com a empresa no Brasil. Até o momento não buscaram outras alternativas para internacionalizar. O sócio, com quem foi realizada a entrevista, fez algumas observações interessantes que podem contribuir com o debate:

[...] Tivemos uma visão conservadora; se tivesse arriscado, apostado mais [...] pesou contra a gente. [...] a questão toda está em cima da falta de experiência mesmo. De você ter a oportunidade de atuar fora do país, só que você não está preparado. A gente não fez nenhum estudo de mercado. Mercado não só de marketing e comercial, mas de entender a realidade do mercado mesmo. A gente confiou na visão míope de um cliente que tinha interface com a gente e com eles lá. Ele fez uma leitura simples. [...] A gente devia ter feito: vamos lá conhecer, visitar, sentar e discutir. E se eu fosse vender para os acionistas eu venderia diferente. [...] Se a gente tivesse explorado o mercado e entendido a realidade deles. Lá é outra realidade, teria feito uma imersão.

\section{Objetivos Educacionais}

Pretende-se desenvolver nos participantes:

1) Familiaridade com a realidade empresarial nas questões pertinentes ao processo de internacionalização de negócios;

2) Respostas cognitivas e emocionais quanto a esta realidade;

3) O estudo e crítica da literatura sobre teorias de internacionalização e modos de entrada em mercados internacionais; 
4) Análise reflexiva e busca de estratégias para resolução do caso, bem como aplicação em situações próximas ao cotidiano do aluno.

As informações contidas no caso foram idealizadas para a utilização em cursos pós-graduação stricto e lato sensu e MBA em Administração de Empresas e Internacionalização de Empresas nas disciplinas de Teorias de Internacionalização e Estratégias de Internacionalização de Negócios. Optou-se por trabalhar questões pertinentes aos modos de entrada em mercado internacional e às teorias de internacionalização. No entanto, o caso permite o desenvolvimento de reflexão em outras áreas de atividade empresarial: em Estratégia com o estudo da RBV (Visão Baseada em Recursos) (BARNEY et al., 2001); em Estratégias de Internacionalização, com a análise da influência dos recursos nas dificuldades de internacionalização (CUERVO-CAZURRAL; MALONEY; MANRAKHAN, 2007) e com a reflexão sobre as alianças estratégicas para competição internacional com produtos inovadores e intensos em tecnologia (MARIOTO, 2007).

\section{Fontes de Obtenção de Dados}

O caso foi desenvolvido utilizando-se de fontes primárias e secundárias. De fonte primária realizou-se a entrevista semiestruturada com um dos sócios da empresa. De fonte secundária, realizou-se pesquisas no site da empresa.

\section{Utilização Recomendada - Tópicos Pedagógicos}

A proposta de estudo do caso pode ser organizada da seguinte forma:

a) Leitura e análise individual realizada por aluno antes da aula;

b) Análise e discussão do caso em pequenos grupos na sala de aula à luz da teoria (tempo sugerido 1 hora);

c) Discussão em sessão plenária, orquestrada pelo professor; 
d) Fechamento da discussão com o desenvolvimento do quadro de questões básicas para o processo de internacionalização de uma empresa (conforme sugerido no Quadro 1 das notas de ensino).

\section{Referências:}

ANDERSON, E.; GATIGNON, H. Modes of Foreign entry: a transaction cost analysis and propositions. Journal of International Business Studies, v. 17, n. 3, p. 1-26, 1986.

BARNEY, J. B.; WRIGHT, M.; KETCHEN, D. J. The resource based view of the firm: Ten years after 1991. Journal of Management, v. 27, n. 6, p. 625-641, 2001.

CARNEIRO, J.; DIB, L. A. Avaliação Comparativa do Escopo Descritivo e Explanatório dos Principais Modelos de Internacionalização de Empresas. . INTERNEXT - Revista Eletrônica de Negócios Internacionais da ESPM, v. 2, n. 1, p. 1-25, 2007.

CUERVO-CAZURRAL, A.; MALONEY, M. M.; MANRAKHAN, S. Causes of the difficulties in internationalization. Academy of International Business. Journal of International Business Studies, v. 38, n. 5, p. 709-725, 2007.

DUNNING, J. F. The Eclectic Paradigm of International Production: a restatement and some possible extensions. Journal and Marketing Business Studies, v. 19, n. 1, p. 1-31, 1988.

JOHANSON, J.; MATTSSON, L. Internationalization in Industrial Systems - A Network Approach. In: HOOD, N.; VAHLNE, J. (Ed.). Strategies in Global Competition. New York: Croom Helm, 1988, p. 287-324.

JOHANSON, J.; VAHLNE, J. The Uppsala internationalization process model revisited: From liability of foreignness to liability of outsidership. Journal of International Business Studies, v. 40, n. 9, p. 1411-1431, 2009.

MARIOTTO, P. P. et al. Estratégia Internacional da Empresa. São Paulo: Thomson Learning, 2007.

' Casos de ensino passam somente pela avaliação do editor da Regepe. 